\title{
PERE PASQUAL, \\ FILL I RECTOR DE LA FATARELLA, CAPELLÀ \\ DEL REI PERE EL CERIMONIÓS, I L'ORIGEN DEL CULTE \\ A LA MARE DE DÉU DE LA MISERICÒRDIA \\ (SEGLE XIV)
}

JOSEP ALANYÀ I ROIG ${ }^{1}$

Resum: L'article presenta les dades biogràfiques descobertes a I Arxiu Reial de Barcelona del prevere tortosí Pere Pasqual, fill i rector de La Fatarella, capellà i domèstic de Pere el Cerimoniós, i posa la seva figura en relació amb Porigen del culte i la presència de la imatge alabastrina de la Mare de Déu de la Misericòrdia a la capella de la Torre de l esmentada vila.

Paraules clau: Clergat; Religiositat; Catalunya; Pere el Cerimoniós; Segle XIV.

Abstract: The aim of this article is to offer some biographic information-brought to light from the Archivo de la Corona de Aragón (Barcelona)-, about Pere Pascual, a clergy born in La Fatarella, who became the priest of the Parish of his town and the Chaplain of Peter the Cermonious. The author relates that priest with the worship to the alabastre image of the Mare de Déu de la Misericòrdia, that is honoured in the Capella de la Torre of the named town.

Keywords: Clergy; Piety; Catalonia; 14th century; Peter the Cerimonious.

\section{SUMARI}

I. L'església de la Misericòrdia.- II. La imatge.- III. La Fatarella en temps del rector Pasqual.- IV. Pere Pasqual, rector de La Fatarella, capellà reial.- Fonts i bibliografia.

${ }^{1}$ Director de l'Arxiu Històric Diocesà de Tortosa.

Data de recepció de l'article: juny 2005. Data d'acceptació i versió final: juliol 2005.

«Anuario de Estudios Medievales», 35/2 (2005), pp. 951-970 .- ISSN 0066-5061. 


\section{L'ESGLÉSIA DE LA MISERICÒRDIA}

Quan hom arriba a La Fatarella, una de les dotze viles històriques de la Terra Alta, hom veu dominant el nucli urbà, aixecada sobre un turó, l'església de la Mare de Déu de la Misericòrdia, que guarda una imatge alabastrina del segle XIV, portada a la vila pel rector Pere Pasqual.

L'església és un edifici barroc sumptuós, de planta de creu llatina, tres naus cobertes amb voltes de canó amb llunets, cúpula i campanar de cadireta, construit entre els anys 1789 i 1793 pel mestre d'obres Francesc Melet, de Fraga, mestre també de les esglesies de Batea, Corbera d'Ebre i Amposta, i de la sagristia major de la catedral de Tortosa, que cobrà, per la direcció i execució de l'obra, 1.600 lliures d'ardits. L'església ocupa l'indret d'una antiga torre àrab de guaita i defensa integrada en la xarxa de torres aixecades ja en temps ibèric damunt el territori de l'Ebre des de la mar, a Tortosa, fins al Pirineu de Lleida i l'interior de la Península Ibèrica.

El rector Domingo Mauri ${ }^{2}$ diu de la torre:

Descendiendo hacia Occidente desde la cumbre que remata la escarpada pendiente de Ascó y atravesando un bosque feroz contra el cierzo que agita sus corpulentos pinos y remueve sus malezas, donde merodean el lobo y la culebra, y salta el conejo y la perdiz canta y el mirlo, y anida la paloma silvestre y grazna el cuervo; a los tres cuartos de hora, sorprende al viajero la presencia de una torre mora, algo desmochada, negruzca... levantada al frente, sobre una loma de la accidentada meseta de las montañas de la derecha del Ebro, a diez kilómetros de su tersa y caudalosa corriente (...)

En torno de ella gira casi toda la historia religiosa local en lo que dice relación al culto de la Santísima Virgen en su etapa de más fervor y entusiasmo.

Sería esta torre cuadrada, al estilo árabe, y almenada, no prismática (como se ve en un grabado del archivo de 1609). Así parece desprenderse de algunas referencias.

${ }^{2}$ Domènec MAURI I VALlDEPERES (Tortosa, 1874-Gandesa, 1936), prevere (1901) i escriptor, fou coadjutor i després regent de La Fatarella, ecònom de Tivissa, rector de Corbera i arxiprest de Gandesa (1915), on morí assassinat durant la revolució de 1936. Fou erudit en ciències eclesiàstiques i publicà La Misericordia. Apunte histórico-descriptivo de su imagen y santuario de Fatarella (1913), Mi Esperanza o Novena a Nuestra Señora de la Misericordia (1915), Sermón de la Santa Cinta (1926) i Antología eclesiástica o Vocabulario de las principales cosas que sobre Derecho canónico y Civil, Liturgia, Historia, etc. más interesan a los párrocos y demás clero de España, compuesto con arreglo al actual Código de la Iglesia y a nuestras vigentes leyes patrias (1929). Cfr. Ramon MIRAVAll I DolC, Mauri $i$ Valldeperes, Domènec, a Diccionari d'història eclesiàstica de Catalunya, II, p. 597; Manuel GARCIA I SANCHO, Sacerdots diocesans fidels fins al martiri. Diòcesi de Tortosa 1936-1939, p. 371.

«Anuario de Estudios Medievales», 35/2 (2005), pp. 951-970 .- ISSN 0066-5061. 
Estaba emplazada en el extramuro meridional, sobre el montecillo donde se alza hoy la Misericordia; respondía perfectamente, por su posición estratégica, al fin guerrero que allà la puso. Era una excelente atalaya.

Se llamó esta torre FATORELLA, de donde tomó su nombre la actual población que acabó por adoptarla en su sello y señalar con ella los objetos del culto y edificios religiosos. Hoy se la reproduce con una estrella sobre sus almenas (...) Allí permaneció la torre, solitaria y abandonada durante varios siglos, hasta que se la convirtió, al fin, en santuariode la Virgen³.

La torre havia estat ja escollida per la Confraria del Roser com a seu pròpia el mateix any de la seva fundació a la vila, el 1571, d'acord amb la petició presentada a fra Lluís Martí, dominicà del convent de Sant Domènec de Tortosa, per fra Cebrià Rius, de La Fatarella, frare del mateix convent: "Senyallós después pera esta Capella la torre de la dita vila, segons que el Frare Sebrià Rius m'ho havia apuntat en Tortosa..." Però el mal estat de la torre en aquell moment obligà els confrares a fer-hi obres i endreçar l'indret i així, segons nota de fra Lluís Martí, "anàrem a la torre tots i la fitàrem i en tres dies se donaren tan bona pressa los treballadors que feren lo camí i paredaren tot lo fité de la torre fins a més de mitant paret i plantà lo senyor Mosèn Hieroni Miró molts rosers en lo camí i molts seps". La fundació de la confraria fou autoritzada pel bisbe diocesà Martín de Córdoba. Beneí les obres de la torre convertida en capella el vicari de Les Camposines, Andreu Monlleó, i hi celebrà la primera missa el rector de la parròquia de Sant Andreu Apòstol, Jaume Franch, d'Ascó ${ }^{4}$.

Tanmateix la capella de la torre serví poc de temps de seu a la confraria del Roser perquè el lloc era desert, quedava apartat i extramurs del clos urbà i, exposat als vents, al fred rigorós i a les freqüents glaçades de l'hivern, era incòmode als confrares d'anar-hi per als actes de confraria i ferhi des de l'església parroquial la processó preceptiva de Dominica cada mes. Per això, transcorreguts trenta-quatre anys, la torre quedà abandonada novament després que els confrares, el 3 d'abril de 1604, decidiren de traslladar la seu a l'altar de l'Assumpció del temple parroquial d'acord amb la llicència atorgada i signada al convent de Santa Caterina de Barcelona pel P. Provincial de l'Orde de Predicadors de la Província d'Aragó en la data esmentada.

\footnotetext{
${ }^{3}$ Domingo MAURI, La Misericordia. Apunte histórico-descriptivo de su imagen y santuario de Fatarella, pp. 3-8.

${ }^{4}$ Ibidem, pp. 10 i 50, nota D.

«Anuario de Estudios Medievales», 35/2 (2005), pp. 951-970 .- ISSN 0066-5061.
} 
Havent restat buida i sense culte la capella de la torre, la municipalitat i la parròquia la dedicaren a la Mare de Déu de la Misericòrdia i hi dipositaren la bella imatge gòtica guardada fins aleshores a l'església parroquial, on havia presidit un bell retaule d'alabastre, potser ja malmès i desmuntat. La primera notícia d'aquesta capella de la Misericòrdia l'hem trobat en les actes de la visita pastoral del bisbe Pedro Manrique a la parròquia de La Fatarella l'any 1608 , on consta que concedí quaranta dies d'indulgència a tots aquells que resessin cinc vegades el parenostre amb l'avemaria tot visitant "la capilla de Nuestra Señora de la Misericordia, fundada en la torre de la Fatarella"5. El bisbe Manrique volia òbviament fomentar la devoció a la Mare de Déu just en el moment en què hi havia perill que la imatge quedés oblidada un cop extreta del temple parroquial i quan els nous gustos del darrer Renaixement i del primer Barroc amenaçaven d'infravalorar l'art medieval.

La devoció mariana anà creixent prou ràpidament centrada en la imatge de l'anomenada Marededéu de la Torre i hom dotà el culte de fundacions pies i beneficis eclesiàstics ${ }^{6}$. Durant el temps que s'esmerçà a construir la nova església parroquial a càrrec de la municipalitat i amb importants aportacions del cardenal Agustí Spínola, bisbe de Tortosa, i del rector, la capella de la Torre serví de temple parroquial, circumstància que hauria contribuilt a consolidar-se el culte marià centrat en l'antiga imatge.

En un segle de fort creixement demogràfic de la vila, d'anys econòmicament pròspers i d'un afiançament de la devoció enfront de les idees racionalistes i il-lustrades que arribaven d'Europa com fou el XVIII, els fatarellencs decidiren d'enderrocar l'antiga capella de la Torre, poc capaç, senzilla i amb problemes de conservació, i aixecaren de nova planta l'església actual, vora la qual hi ha hagut fins al segle XX el cementiri construit arran de la Reial Cèdula de 1787 que manava treure els fossars dels nuclis urbans. Així l'església de la Misericòrdia féu funció de capella del cementiri i fou també lloc d'inhumació de famílies devotes i, especialment, del rector Josep Compte i Rius, privilegiat per haver contribuït generosament amb els seus béns a l'obra nova i al seu embelliment, com consta a la llosa sepulcral que hi ha prop del presbiteri.

${ }^{5}$ Arxiu Capitular de Tortosa, Visites Pastorals. Bisbe Pedro Manrique. Any 1608. La Fatarella, s. f. XIX.

${ }^{6}$ Arxiu Històric Diocesà de Tortosa (AHDTo), Causes Beneficials. La Fatarella, s. XV-

«Anuario de Estudios Medievales», 35/2 (2005), pp. 951-970 .- ISSN 0066-5061. 


\section{LA IMATGE}

La imatge de la Mare de Déu de la Misericòrdia de La Fatarella és avui l'única imatge antiga que s'ha salvat d'una total destrucció d'entre totes les escultures de la Verge Maria que eren venerades en esglésies parroquials i capelles de la comarca de Terra Alta. Ho lamentem i fem costat a l'historiador de l'Art Antoni José i Pitarch quan se'n lamenta dient que "per desgràcia no s'han conservat un gran nombre de les imatges de la Mare de Déu que, especialment des de la meitat del segle XIV, presidien moltes de les esglésies parroquials de tot Catalunya, bé de manera aillada, bé formant part d'un retaule, peça litúrgica bàsica en aquell temps, i encara ha estat menor el nombre d'imatges conservades realitzades en pedra o en alabastre. Sembla com si aquesta matèria hagués estat més propícia per a la desaparició de les obres"7. L'escassetat d'imatges obrades en aquesta matèria al Principat i el fet que la de La Fatarella sigui única a la comarca fan més valuosa la imatge tot i els adobs i refeccions deficients que mostra com a conseqüència de les destrosses causades el juliol de 1936. "A aquest propòsit -diu José i Pitarch - fóra convenient que allò que va quedar trencat i perdut de la imatge no quedés desmillorat per les restauracions."

La imatge és una escultura d'alabastre amb restes de policromia que fa $79 \mathrm{~cm}$ d'alt i representa la Verge Maria amb el Nen Jesús, de $33 \mathrm{~cm}$ d'alt, portant a la mà dreta una poma i sostingut pel braç esquerre de la mare, qui amb la mà dreta acarona la mà esquerra del fill. La imatge descansa damunt una peanya octogonal d'alabastre adornada amb quadrifolis. La Verge vesteix túnica de mànigues llargues, botonades a nivell del canell, i mantell cordat a nivell del pit per un fermall, ornats amb una fina sanefa de fulles, i porta el cap tocat amb vel. El Nen vesteix túnica de mànigues llargues botonades, adornada amb una sanefa de fulles i cenyida amb un cinturó, i duu al coll un penjoll en forma de medalla circular pendent d'un cordó. Cal atribuir-la a la segona meitat del segle $\mathrm{XIV}^{8}$.

Des que coneguérem l'existència de mossèn Pere Pasqual i la seva relació amb la casa reial d'Aragó, així com la datació de la imatge, vàrem

${ }^{7}$ Antoni José i PITARCh, La Mare de Déu de la Fatarella, a "La Mare de Déu de la Misericòrdia a la Fatarella", p. 23.

${ }^{8}$ Josep ALANYÀ I RoIG, Etnografia de la Terra Alta, pp. 69 i 472. ÍDEM, Sermó de la Mare de Déu de la Misericòrdia en el segon centenari de la construcció de la capella (1793-1993), Barcelona, Altés, s.1., 1993.

«Anuario de Estudios Medievales», 35/2 (2005), pp. 951-970 .- ISSN 0066-5061. 
pensar que era realitzada per un escultor pertanyent als obradors de la Cort, més concretament al nucli d'artistes actius a Poblet i al cercle de Jaume Cascalls. Apel-lant a la seva competència i autoritat en art medieval, no dubtàrem d'acudir al bon amic Antoni José i Pitarch, catedràtic d'Història de l'Art a la Universitat de Barcelona, per demanar-li un estudi analític de la imatge que ens permetés confirmar la nostra hipòtesi.

El professor Antoni José i Pitarch, quan li vàrem comentar l'existència de la imatge de La Fatarella, s'estranyà de la presència d'una imatge d'aquestes característiques a la Terra Alta, puix tenia comprovat que "la geografia de l'escultura catalana de la segona meitat del segle XIV no inclou, generalment, les terres de l'Ebre o vinculades a la ciutat de Tortosa, sinó que es manté més al voltant de la Cort, dels centres que en depenien o que hi estaven estretament vinculats -Poblet- i d'altres derivats dels nuclis de la Cort, bé que amb independència de treball - per exemple Lleida". Però quan li donàrem notícia de mossèn Pere Pasqual, fill i rector de La Fatarella i capellà i domèstic de la casa reial de Pere el Cerimoniós, a l'expert historiador de l'Art se li posaren a punt totes les connexions lògiques aplicades al cas $\mathrm{i}$, atesa la primera premissa (l'escultura relacionada amb la Cort reial) i la segona (que cap centre d'escultura no actua des de Tortosa en aquelles dates "per bé que les làpides funeràries del claustre de la seu de Tortosa assenyalarien l'activitat puntual d'un taller d'escultura al cap de la diòcesi"), conclogué que "per tant, cal situar aquesta imatge de la Mare de Déu en el context dels treballs escultòrics emanats de la Cort - la de Pere el Cerimonióscorresponent a la relació entre La Fatarella i el rei per mitjà de Pere Pasqual, capellà reial i, alhora, rector de la parròquia de La Fatarella, almenys des de $1374 "$.

"És per aquesta via - afirma José i Pitarch-que la figura de la Mare de Déu -o el retaule sencer- degué arribar a aquesta població llunyana dels centres de producció escultòrica. I és per aquesta via que ens és permès d'incloure la imatge en el conjunt genèric de l'escultura del darrer terç del segle XIV, per comparança amb altres obres conegudes, anònimes o amb paternitat documentada. La temporalitat de la referència documental esmentada coincideix amb les característiques formals, amb el tractament físic de la imatge"'. I, fent recurs a l'estudi comparatiu d'obres escultòriques contemporànies que podien permetre aclarir per via demostrativa l'origen $\mathrm{i}$

${ }^{9}$ Ibídem, p. 23.

«Anuario de Estudios Medievales», 35/2 (2005), pp. 951-970 .- ISSN 0066-5061. 
autoria de la imatge, afegeix: "Si hagués de destriar una única font o una única obra com a referència per a l'escultura de la Mare de Déu de La Fatarella, no hi ha dubte que ens hauríem de decantar cap al retaule dels Sants Bernat i Bernabeu de l'església de Santa Maria de Montblanc, per bé que amb algunes diferències. Potser, el paral-lelisme més immediat és el que s'estableix en comparar el rostre de la nostra imatge amb els de les figures de la predel·la del retaule montblanquí. Aquestes, que representen santes màrtirs coronades, defineixen, quant al rostre, tipus semblants al de la Verge de la Fatarella: rostre dens i de faccions fortes; arcs superciliars baixos i estirats; nas prominent; barbeta forta; ulls molt ametllats. Fora de la comparança de la tipologia del rostre, altres parts de la imatge també denoten una vinculació estreta al retaule de Montblanc. Així, els ulls ametllats són molt pròxims als dels dos sants del retaule, mentre que la manera de configurar els cabells del Nen Jesús, pentinats densament i llisa, són en la línia dels que apareixen a la figura de sant Bernat de l'esmentat retaule. Però és la manera de representar les mans dels personatges la que, juntament amb les semblances dels rostres, millor estableix la relació entre la mare de Déu i el retaule de Montblanc. Unes mans amples i llargues, amb dits llargs i carnosos, són les de la Mare de Déu i les del Nen Jesús, de la mateixa manera que ho són les de sant Bernat (la mà esquerra que sosté un llibre), i de sant Bernabeu (la mà dreta que també sosté un llibre). No es tracta de simples paral-lelismes o coincidències de solucions" 10 .

Pel que fa al taller i a l'autoria, incerta, conclou: "Sense afirmar que la Verge de La Fatarella procedeix del mateix taller que el retaule de Montblanc, sí que cal dir que l'autor de la Mare de Déu tenia relació amb l'obrador que esculpí el retaule dels sants Bernat i Bernabeu, emparentat amb els tallers que treballaven per a la Cort, en una cronologia de les dècades de 1360-1380. A la fi, la Mare de Déu de La Fatarella ve a recollir, anys després, el model de mare de Déu que coneixem, especialment, des del 1345 al retaule de Cornellà de Conflent, obra de Jaume Cascalls de Berga. I no oblidem que Cascalls, juntament amb el mestre Aloi de Montbrai, fou l'autor de nombroses tombes reials de Poblet, és a dir, lligat a Pere el Cerimoniós, lligat a la Cort. Per això, des de Poblet, des de Lleida o des de Montblanc, des d'un obrador que coneixia perfectament l'escultura dels principals mestres de la corona va poder sortir la imatge de La Fatarella, desplaçada del seu punt

\footnotetext{
${ }^{10}$ Ibidem, p. 24.
}

«Anuario de Estudios Medievales», 35/2 (2005), pp. 951-970 .- ISSN 0066-5061. 
d'origen, però justificada per uns contactes directes, molt probablement per mitjà del rector Pere Pasqual"11.

A l'Edat Moderna, el P. Narcís Camós recull la devoció secular dels fills de La Fatarella a la Mare de Déu de la Misericòrdia fent-se alhora ressò de les altres imatges de Maria de Natzaret venerades a la Terra Alta: la del Portal, a Batea, la de la Fontcalda, a Gandesa, la dels Àngels, a Orta, i la dels Dolors, a Vilalba ${ }^{12}$. És el Jardí de Maria a l'antiga Castellania d'Amposta.

\section{LA FATARELLA EN TEMPS DEL RECTOR PASQUAL}

$\mathrm{Al}$ temps que es va esculpir la imatge alabastrina de la Mare de Déu de la Misericòrdia, segons dades del fogatge de $1378^{13}$, La Fatarella tenia 66 focs i era, després de Vilalba dels Arcs, que en tenia 82, la vila més poblada de la comanda hospitalera d'Ascó, puix Berrús només en tenia 4; la Torre d'En Espanyol, 8; Riba-roja, 17; Vinebre, 18; Les Camposines, 14; i Ascó en tenia 45. Amb 66 focs, li corresponia a La Fatarella una població de 264 habitants, una població que havia minvat força si tenim en compte que el cens de 1358 manifesta 83 focs i, per tant, una població que ultrapassava els 400 habitants.

Les contribucions reials que aportava la vila en aquell temps eren notables, 151 morabatins clars l'any $1350^{14}$, i 1.092 sous jaquesos en el Morabetí de $1380^{15}$, quan La Pobla de Massaluca en pagà 245, Riba-roja 273, Berrús 42, la Torre d'En Espanyol 119, Vinebre 224, Les Camposines 231, i Ascó 756, dels quals 161 eren contribució de cristians i 595 dels sarraïns; només Vilalba li anava al davant amb 1.323 sous jaquesos.

El rector de la parròquia de Sant Andreu de La Fatarella pagava religiosament els delmes que li pertocava de satisfer al rei Jaume II el Just de tots els rèdits i guanys que li corresponien per la rectoria i que el monarca,

\footnotetext{
${ }^{11}$ Ibidem, p. 24.

${ }^{12}$ Narciso CAMós, Jardín de María, plantado en el Principado de Cataluña, Barcelona, 1657, p.164.

${ }^{13}$ Arxiu de la Corona d'Aragó, Reial Patrimoni, Mestre Racional (en endavant ACA, RP, MR), reg. 2591, fols. 63 r.- 67 r.

${ }^{14} \mathrm{ACA}, \mathrm{RP}, \mathrm{MR}$, reg. 2406. Llocs de la Castellania d'Amposta.

${ }^{15}$ ACA, RP, MR, reg. 2407, lligall 1.

«Anuario de Estudios Medievales», 35/2 (2005), pp. 951-970 .- ISSN 0066-5061.
} 
per concessió del papa Joan XXII, destinava a la conquesta de Sardenya. L'estimació de les rendes rectorals era de 650 sous, pels quals hom pagà en dos anys (1325-1326) 97 sous i 6 diners $^{16}$. En la col-lecta de la Dècima triennal de 1371, el rector de La Fatarella estimava els béns de la rectoria en 700 sous, pels quals va satisfer al rei Pere el Cerimoniós 65 sous ${ }^{17}$. Dues dècades més tard, en la Dècima triennal que el bisbat de Tortosa havia de lliurar a mans del rei Joan I l'any 1393, el rector de La Fatarella estimava els seus béns en 650 sous, pel quals pagà, en tres anys, 65 sous. Els documents d'arxiu ens donen notícia de dues capellanies erigides a l'església de La Fatarella que també pagaren la Dècima: la capellania de Guillem Figueret, amb béns estimats en 240 sous, que en pagà 24 , i una altra capellania innominada - molt probablement la de Santa Maria, de recent fundació aleshores-, amb béns estimats en 200 sous, que en pagà $20^{18}$.

La parròquia de La Fatarella pertanyia a l'arxiprestat de Gandesa i a l'oficialat eclesiàstic de Tortosa. L'església era de patronat municipal, la qual cosa implicava que la universitat, consell i jurats de la vila havien de tenir cura de l'edifici, de l'altar major, de les jocalies, llibres, ornaments litúrgics, campanes, i també de les despeses de cera i oli per a les llànties. Tenia rector, en algun temps també vicari coadjutor, $\mathrm{i}$ beneficiats de les capellanies que solien ésser preveres, diaques o clergues tonsurats naturals de la vila $\mathrm{i}$ emparentats amb llurs respectius fundadors.

La vila, poblada l'any 1228 pel preceptor templer de la Ribera d'Ebre en carta atorgada a Pere de Fortea, formà part originàriament de la comanda d'Ascó juntament amb Riba-roja, Berrús, Les Camposines, Ascó, Vinebre, l'antic lloc i terme de Gorrapte, Vilalba i la Torre d'En Espanyol. En el darrer quart del segle XV fou separada d'Ascó i restà integrada dins la nova comanda de Vilalba amb Berrús, Riba-roja i Torrent de Cinca.

La Fatarella, com les altres viles de la comanda d'Ascó i les de la batllia de Miravet, es regia pels Costums de Lleida i pels Usatges de Barcelona en les causes civils i en les criminals, això és per fur i lleis de Catalunya i no pas per fur de Saragossa com pretenien abusivament i il-legítima les autoritats aragoneses de regir-se els pobles de la Castellania

\footnotetext{
${ }^{16} \mathrm{ACA}, \mathrm{RP}, \mathrm{MR}$, reg. 1773 , fol. $12 \mathrm{r}$.

${ }^{17} \mathrm{ACA}, \mathrm{RP}, \mathrm{MR}$, reg. 1824 , fol. $11 \mathrm{r}$. XIV.

${ }^{18} \mathrm{ACA}, \mathrm{RP}, \mathrm{MR}$, reg. 1884 , fols. 5 v. i 8 r. AHDTo, Causes Beneficials. La Fatarella, s.

«Anuario de Estudios Medievales», 35/2 (2005), pp. 951-970 .- ISSN 0066-5061.
} 
d'Amposta situats a la dreta de l'Ebre. Usatges de Barcelona i Costums de Lleida foren els codis legals escollits pels templers perquè els seus vassalls, sobre els quals hi tenien mer i mixt imperi, en regissin llur vida individual i social ${ }^{19}$. Usatges i Costums sobre els quals, com a pauta, a més del Dret Comú i del Canònic com a supletoris, els templers redactaren els Usos i Costums d'Orta el 1296, per a la comanda d'Orta, i els hospitalers, el 1319, els Costums de la Batllia de Miravet per a la Castellania d'Amposta.

En tant que membre de la comanda d'Ascó la vila de La Fatarella es beneficià del privilegi que Jaume II concedí a la comanda i a les viles i llocs que la formaven amb motiu de l'acolliment i els grats serveis prestats al rei pel comanador d'Ascó, Berenguer de Sant Marçal, i els seus vassalls en la persona de la reina Blanca de Nàpols per tot el temps que hagué de romandre a Vinebre per causa d'un part. El privilegi reial, atorgat a Tarragona el 7 de gener de 1319, consistia a no pagar de dret de cena més que 200 sous jaquesos cada any tota la comanda ${ }^{20}$.

Aquest privilegi anava bé als pobladors de La Fatarella i comarca perquè els anys del segle XIV foren generalment pobres de collita per falta de pluja; i les epidèmies, greus i sovintejades, causaven no poques defuncions $\mathrm{i}$, per tant, una minvança demogràfica important, i les guerres generals i comarcals, com la dels dos Peres i la de Tortosa contra la Castellania d'Amposta, arruïnaven les economies familiars i buidaven les caixes de tres claus dels municipis. És per això que sovint trobem enregistrats en els llibres de la Cancelleria Reial del segle XIV ajornaments de satisfacció de deutes, sol-licitats al rei perquè als deutors els era impossible de pagar-ne les quantitats en el temps i terminis prefixats per causa de les males anyades, de les mortaldats o de les guerres. No descartem que fos aleshores i arran d'aquestes desgraciades situacions que, amb encert, els pobladors de $\mathrm{La}$ Fatarella invoquessin la Mare de Déu, que veneraven dins el temple antic en la imatge gòtica alabastrina, amb el títol de Mare de Déu de la Misericòrdia,

\footnotetext{
${ }^{19}$ Josep AlanYÀ I RoIG, Els Costums d'Orta i el fur de Saragossa, dues arrels per a un conflicte, a "700 anys dels Costums d'Orta. Actes de les Jornades d'Estudi" (1996), pp. 243-268. Josep SERRANo DAURA, Senyoriu i municipi a la Catalunya Nova (segles XII-XIX), I, pp. 128133.

${ }^{20}$ Arxiu de la Corona d'Aragó, Cancelleria (en endavant, ACA, C), reg. 217, fol. 236 r.v. «Anuario de Estudios Medievales», 35/2 (2005), pp. 951-970 .- ISSN 0066-5061.
} 
malgrat que la imatge no presenta cap atribut de l'advocació sota la qual secularment és venerada ${ }^{21}$.

En el llibre de la visita pastoral que el bisbe de Tortosa Francesc de Paholac féu a la diòcesi l'any 1314 La Fatarella, visitada el 2 de desembre, és, entre totes les de la comarca, la vila amb més moralitat. Segons declaració dels jurats del municipi, Julià Tallada i Bernat Queixalós, i dels veïns Francesc Alfaig, Joan de Vernet i Pere Ça Font, ningú no moria sense rebre els sagraments; els béns econòmics de la parròquia es destinaven als usos de l'església i, per això, aquesta estava ben dotada de jocalies, llibres litúrgics i ornaments, disposava de servidors idonis per a l'exercici de les tasques i funcions d'església i hom podia complir satisfactòriament amb el deure de l'hospitalitat cristiana envers els pobres, els malalts i els pelegrins. El rector anava palesament tonsurat i vestia amb decència l'hàbit talar. Entre els feligresos no hi havia pecats de blasfèmia, de sortilegi o de sacrilegi ni tampoc homicidis. No es donaven tampoc casos d'ocultisme, màgia negra o diabòlica, heretgia o creences desviades, ni casos de concubinat, de jocs de daus i d'atzar, ni tampoc negocis amb usura, així com no hi havia cap cas de simonia en l'exercici del sacerdoci, en l'administració dels sagraments ni en el servei i administració dels beneficis eclesiàstics. Tan solament declarà el rector, Berenguer de Torrent, que un veí, Tomàs Centull, feia contractes amb usura en la venda d'animals de labor, i que un altre veí, Tomàs Pucullull, era sospitós de tenir relacions il-lícites amb una dona que es deia Arseneta ${ }^{22}$.

\section{Pere Pasqual, ReCtor de La Fatarella, CAPELLÀ REIAL}

Fent recerca en els fons de la Cancelleria Reial de l'Arxiu Reial de Barcelona ens ha sorprès el nombre de clergues tortosins afavorits pels monarques d'Aragó, d'entre els quals mereixen menció especial l'arxiprest de

\footnotetext{
${ }^{21}$ La Mare de Déu de la Misericòrdia és representada donant protecció sota el seu ampli mantell estès a una multitud que simbolitza el gènere humà i en la qual apareixen el papa, cardenals, bisbes, monjos i monges, frares i clergat secular, i l'emperador, reis i reines, nobles i cavallers, dames, artesans i llauradors, o tota una congregació religiosa.

${ }^{22} \mathrm{M}^{\mathrm{a}}$ Teresa GARCíA EGEA, La visita pastoral a la diócesis de Tortosa del obispo Paholac. 1314, p. 178.
}

«Anuario de Estudios Medievales», 35/2 (2005), pp. 951-970 .- ISSN 0066-5061. 
Morella Domingo Belltall i Vives, home de confiança de Jaume $\mathrm{II}^{23}$; Jaume Ballester, beneficiat de la seu de Tortosa ${ }^{24}$, Guerau Domènech, prevere de Benicarló $^{25}$, Bernat Castella, rector de Tivissa ${ }^{26}$, capellans de Pere el Cerimoniós; Martí de la Cova, rector de Batea $^{27}$, Miquel Sagarra, canonge de Tortosa $^{28}$, i Llorenç Manresa ${ }^{29}$, capellans de Joan I; Berenguer Tarragó, rector d'Orta $^{30}$, Joan de Mora, rector d'Ascó ${ }^{31}$, Ferrer d'Anglesell, rector de La Palma d'Ebre ${ }^{32}$, Bernat Lorach, rector de Traiguera ${ }^{33}$, Bernat Puigalt, beneficiat a Santa Maria de Morella ${ }^{34}$, Ramon Guasch, beneficiat a la seu de Tortosa $^{35}$, i Nicolau Alamany, rector de Catî ${ }^{36}$, capellans del rei Martí I l'Humà; Pere de Garret, rector de Batea ${ }^{37}$, capellà de Ferran d'Antequera; i Arnau Llacuna, beneficiat a la seu de Tortosa ${ }^{38}$, d'Alfons el Magnànim.

Un altre capellà i domèstic del rei Pere el Cerimoniós fou Pere Pasqual, rector de l'església de Sant Andreu de La Fatarella, on era nascut, n'ignorem, però, la data i la seva filiacióo ${ }^{39}$. Sabem per la documentació reial que començà a servir a la capella del monarca l'any 1361 i que aquest l'estimà força i hi confiava en gran manera fins al punt d'encarregar-li tasques

${ }^{23} \mathrm{ACA}, \mathrm{C}$, reg. 381, fol. $201 \mathrm{v}$.

${ }^{24} \mathrm{ACA}, \mathrm{C}$, reg. 1275 , fol. 25 r.v.

${ }^{25} \mathrm{ACA}, \mathrm{C}$, reg. 911, fols. 104 v. -105 r.

${ }^{26} \mathrm{ACA}, \mathrm{C}$, reg. 924, fol. $89 \mathrm{r}$.

${ }^{27} \mathrm{ACA}, \mathrm{C}$, reg. 1690 , fols. 7 r. $-8 \mathrm{r}$.

${ }^{28} \mathrm{ACA}, \mathrm{C}$, reg. 1881 , fol. 51 r.v.

${ }^{29} \mathrm{ACA}, \mathrm{C}$, reg. 1928 , fol. 130 r.v.

${ }^{30} \mathrm{ACA}, \mathrm{C}$, reg. 2134 , fol. 61 r.; reg. 2167, fol. $68 \mathrm{r}$.

${ }^{31} \mathrm{ACA}, \mathrm{C}$, reg. 2172, fol. $14 \mathrm{v}$.

${ }^{32} \mathrm{ACA}, \mathrm{C}$, reg. 2185 , fol. 48 r.v.

${ }^{33} \mathrm{ACA}, \mathrm{C}$, reg. 2185 , fol. $111 \mathrm{v}$.

${ }^{34} \mathrm{ACA}, \mathrm{C}$, reg. 2200 , fol. 141 r.v.

${ }^{35} \mathrm{ACA}, \mathrm{C}$, reg. 2205, fol. $27 \mathrm{v}$.

${ }^{36} \mathrm{ACA}, \mathrm{C}$, reg. 2206, fol. $105 \mathrm{v}$.

${ }^{37} \mathrm{ACA}, \mathrm{C}$, reg. 2395, fol. $152 \mathrm{v}$.

${ }^{38} \mathrm{ACA}, \mathrm{C}$, reg. 2485 , fol. $59 \mathrm{v}$.

${ }^{39} \mathrm{ACA}, \mathrm{C}$, reg. 926, fols. 116 v.-117 r. Josep AlanYÀ I RoIG, El Seminari Diocesà de Tortosa, pp. 33-40.

«Anuario de Estudios Medievales», 35/2 (2005), pp. 951-970 .- ISSN 0066-5061. 
delicades. A ell atribuïm la presència de la imatge de la Mare de Déu de la Misericòrdia a La Fatarella i l'origen del culte i devoció a la preuada imatge gòtica, primer al temple parroquial antic i després a l'església de la Torre.

Del rector Pasqual hi ha abundant documentació en els fons de la Cancelleria Reial, sempre relacionada amb Pere el Cerimoniós i amb el seu primogènit, Joan, duc de Girona i comte de Cervera, i monarca d'Aragó a la mort del seu pare. La primera notícia que hi ha del rector de La Fatarella és de l'any 1363; la darrera menció que hom fa de la seva persona en els documents de l'Arxiu Reial de Barcelona és del 1395, per la qual cosa creiem que la seva mort podria haver-se produït aquell mateix any o el següent i que, en tot cas, no hauria viscut més ençà del 1400 .

En el primer document on apareix el nostre personatge aquest no era encara ordenat de prevere i servia a la capella reial com a escolà i cantor. Pere III li atorgava un salconduit i la pertinent llicència per traslladar-se a la Cort Papal d'Avinyó, on havia de presentar-se per resoldre afers personals. El document reial, signat a la plana de Borriana el 26 de juny de 1363, anava adreçat pel rei Pere el Cerimoniós als seus oficials i als del rei de França:

\begin{abstract}
Petrus, et cetera. Dilectis et fidelibus universis et singulis officialibus nostris seu Illustris Regis Francie, consanguinei nostri carissimi, salutem et dilectionem. Cum fidelis scolaris Capelle nostre Petrus Paschalis, presentium exhibitor, pro certis suis negotiis de nostri permissu apud Avinionem dirigat gressus suos, idcirco vobis, officialibus nostris, dicimus et mandamus aliosque devotos nostros rogamus quatenus eidem Petro in eundo, stando et redeundo nullam molestiam inferatis seu inferre per quempiam permitatis. Quinimo provideatis sibi, cum inde requisiti fueritis, de securo transitu et conductu. Datum in Campis prope Burrianam, XXVI die Junii, anno a nativitate Domini M CCC LX tertio. Johannes Eximini. Bernardus Michaelis, mandato regio facto per Jacobum Conesa, secretarium $^{40}$.
\end{abstract}

Per una carta reial de 19 de març de 1379 enviada al papa de Roma sabem que en aquesta data el rector de La Fatarella feia divuit anys que servia com a capellà al rei Pere el Cerimoniós ${ }^{41}$. El mateix any Mn. Pere Pasqual, "presbitero, de capella Domini Regis", apareix gaudint d'un benefici

${ }^{40} \mathrm{ACA}, \mathrm{C}$, reg. 1187, fol. $225 \mathrm{v}$.

${ }^{41} \mathrm{ACA}, \mathrm{C}$, reg. 1553 , fol. $66 \mathrm{v}$.

«Anuario de Estudios Medievales», 35/2 (2005), pp. 951-970 .- ISSN 0066-5061. 
eclesiàstic a la catedral d'Elna: "in Elnensi Ecclesia Beneficiato de Sancto Cipriano" 42 .

Com a capellà reial de Pere III, mossèn Pere Pasqual rebé l'encàrrec de fer arribar blat d'Aragó i de la Castellania d'Amposta a la ciutat de Barcelona que patia gran necessitat de cereals ${ }^{43}$. Home de confiança del monarca, aquest l'envià al Castellà d'Amposta, fra Martí de Lihori, per fer-li relació del capteniment irregular d'alguns frares santjoanistes de la comanda de Casp, encàrrec que signà el rei Pere a Barcelona el dia 1 de gener de $1386^{44}$.

Uns anys abans, el 30 d'agost de 1377, Pere III escrivia al papa, a diversos cardenals amics i al Cardenal d'Aragó, Pero Martínez de Luna, el futur Benet XIII, demanant per a mossèn Pere Pasqual una canongia $i$ una prebenda de la col-legiata de Jaca, vacants per mort de Marc Bertran, o l'obtenció de la rectoria de Sant Andreu de La Fatarella i un benefici a la catedral de Barcelona i un altre a la catedral de Ciutat de Mallorca, per als quals estava en expectativa:

Dignetur Sanctitas Vestra collationem et provisionem auctoritate ordinaria factas devoto vestro Petro Paschalis, presbitero, devoti filii vestri Petri, Regis Aragonum, capellano, comensali et domestico, de canonicatu et prebenda Ecclesie Collegiate Civitatis Jacce, diocesis Oscensis, vacantibus per mortem Marchi Bertrandi, extra Romanam Curiam defuncti, auctoritate apostolica confirmare vel de ipsis modo previso vacantibus et Petro de novo mandetur providere reservationibus generalibus vel specialibus aut devolucionibus, non obstantibus quibuscumque, seu quod idem Petrus ecclesiam curatam Sancti Andree de la Fatarella, diocesis Dertusensis, et beneficium sine cura in ecclesia Katedrali Barchinonensis diocesis obtineat et quod ad collationem, et cetera Episcopi et Capituli ac singularium personarum eiusdem Ecclesie Barchinonensis auctoritate litterarum Sanctitatis Vestre duas capellanias sive prestimonia et unum beneficium sive officium sine cura expectet ${ }^{45}$.

Consta així mateix que Mn. Pere Pasqual tenia arrendats els béns de la rectoria de La Fatarella a Bernat Martí, veí de la vila, al qual, ja difunt,

\footnotetext{
${ }^{42} \mathrm{ACA}, \mathrm{C}$, reg. 1633 , fol. $179 \mathrm{v}$.

${ }^{43} \mathrm{ACA}, \mathrm{C}$, reg. 926, fols. $116 \mathrm{v} .-117 \mathrm{r}$.

${ }^{44} \mathrm{ACA}, \mathrm{C}$, reg. 1108 , fol. $108 \mathrm{r}$.

${ }^{45} \mathrm{ACA}, \mathrm{C}$, reg. 1233 , fol. $121 \mathrm{v}$. ; reg. 1553 , fols. 50 v. $-51 \mathrm{r}$.

«Anuario de Estudios Medievales», 35/2 (2005), pp. 951-970 .- ISSN 0066-5061.
} 
alguns creditors quedaren a deure unes quantitats de diners i fruits. Essent renitents a pagar, Pere III urgí el lloctinent del Castellà d'Amposta a fer pagar els deutes als hereus de Bernat Martí en document signat a Barcelona el 19 d'octubre de $1377^{46}$. El 8 d'agost del mateix any, Pere III recriminava el mal capteniment del difunt Bernat Martí, "quondam, del dit loch", envers la persona de "Mn. Pere Pasqual, Rector de la Fatarella" perquè essent ell "arrendador e plegador de les rendes de la sua Rectoria per cert temps, lo qual Bernat, mettent vinya, no li ha volgut retre comptes jassia algunes vegades ne sia estat request. E per tal com lo dit Pere Pasqual ha entendre en nostre servei, no pot per la dita raó anar al dit loch de la Fatarella..."

L'any 1380, Pere III, des de la seva actitud d'indiferència en el Cisma d'Occident, escrivia al papa Climent VII d'Avinyó i al de Roma, Urbà VI, demanant-los capellanies i beneficis per a diversos clergues de la Corona d'Aragó, d'entre els quals era el primer Mn. Pere Pasqual, per a qui sol-licitava la provisió d'una canongia a la catedral de Barcelona ${ }^{48}$. El mateix any, el dia 11 de juny, de Barcelona estant, el monarca recomanava "l'amat capellà de la capella nostra e antich servidor nostre en Pere Pasqual, Rector de La Fatarella" a l'oficial eclesiàstic de Tortosa, a fra Berenguer de Bardaixí, comanador d'Ascó, al vicari general del bisbe de Tortosa i a Pere Guillem d'Estanybos ${ }^{49}$.

El rei d'Aragó escrivia al batlle general de Catalunya una carta signada a Saragossa el 10 de juliol de 1381 en què li recomanava el rector de La Fatarella i li comunicava la seva voluntat d'apropiar-se d'un feu senyorial al Vallès Occidental: "Batle general, a nós és estat suplicat per l'amat capellà de la nostra capella en Pere Pasqual que li donem lo feu d'un delma que la casa de Mogoda que fo d'En Berenguer Sent Vicenç, cavaller quondam, e ara és de la almoyna de Barchinona, ha en la parròquia de Santa Perpètua e del qual feu nós, segons que's diu, no havem res sinó la directa senyoria..." ${ }^{50}$. Del mateix any, amb data de 15 de febrer, signat a Saragossa, és el document de guiatge i protecció, un salconduit, del rei Pere III a favor de qui ell anomena "dilectus Capellanus Capelle nostre Petrus Pascalis, Rector Ecclesie

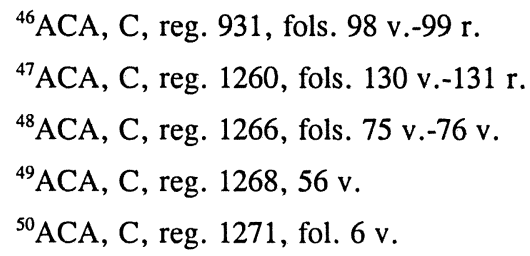


loci de la Fatarella, diocesis Dertusensis ac Beneficiatus in Sede Barchinonensi" ${ }^{\prime \prime}$.

L'any 1383, el monarca abordava des de la indiferència calculada en l'afer del Cisma de l'Església l'assumpte de les xantries i beneficis a les catedrals del seu domini reial i proposava ensems al papa d'Avinyó i al de Roma la provisió d'un benefici o canongia per a Mn. Pere Pasqual a la seu de Lleida $^{52}$.

El rei Joan I, que admirava la personalitat del rector de La Fatarella i la llarga i exemplar fidelitat al seu pare, el rei Pere, manifestava una gran estimació a la seva persona i el féu així mateix capellà seu demanant per a ell el respecte de tots els oficials reials i súbdits de la Corona i tots els privilegis, llibertats i franquícies que pogués tenir, que prou els havia merescut el "dilectus Capellanus noster Petrus Paschalis, presbiter" per tots aquells "graciosis serviciis que... a tempore citra juventutis sue continue prestitis Serenissimo Domino Regi patri nostro memorie recolende tam in eius Capella quam alias et que nobis prompto corde impendere iugiter non desunt, ex quibus optime promeretur apud omnes favorabiliter commendari..." Aquest document era signat a Montsó el 17 de gener de $1389^{53}$.

El mateix to d'agraïment, elogi i amor envers la persona entranyable de mossèn Pere Pasqual es manifesta en uns altres documents de Joan I. Són sengles cartes de singular recomanació enviades als bisbes de Tortosa i Barcelona a favor del "amat Capellà nostre En Pere Paschal, Rector dins lo vostre bisbat de Tortosa, al qual, axí per los serveys que ha fets al senyor Rey En Pere, de gloriosa memòria, pare nostre, com per aquells que ha fets e fa a nós, nos tingam a ell per obligats afectuosament, vos pregam quel dit Pere Paschal e béns seus vullats haver singularment per recomenat" ${ }^{34}$.

El favor reial envers el rector de La Fatarella arribà fins a la cort papal d'Avinyó. Joan I va enviar una ambaixada a Benet XIII sol-licitant per al seu capellà reial, qui ho havia estat del seu pare, el rei Pere, una acumulació de beneficis i oficis eclesiàstics de renda fins a 100 lliures sense perdre la rectoria de Sant Andreu de La Fatarella:

${ }^{51} \mathrm{ACA}, \mathrm{C}$, reg. 936 , fols. 80 v. $-81 \mathrm{v}$.

${ }^{52} \mathrm{ACA}, \mathrm{C}$, reg. 1756 , fols. 64 v. $-65 \mathrm{r}$.

${ }^{53}$ ACA, C, reg. 1894 , fol. 173 r. Cfr. etiam reg. 1958 , fol. 14 r.v. Document datat a Montsó el 28 de febrer de 1389 .

${ }^{54} \mathrm{ACA}, \mathrm{C}$, reg. 1881 , fol. 71 r.; 76 v. Cfr. reg. 1854 , fol. 31 r.v. 


\begin{abstract}
quatenus dilecto Capellano suo, Petro Paschalis, presbitero, qui per XXV annos et ultra in Capella dicti genitoris sui servivit, specialem graciam faciens de uno, duobus, tribus aut pluribus beneficiis sive officiis sine cura quotquot fuerint usque ad quantitatem $\mathrm{C}$ librarum tunc parvorum scriptis communiter vel divisim ad collacionem et eciam Episcopi et Capituli singulariumque personarum Ecclesie Ilerdensis... eciam si in Ecclesia cathedrali Civitatis vel diocesis vacat vel vacare ad presens vel cum simul vel succesive vacabunt, eidem Petro dignemini providere. Non obstante quod idem Petrus ecclesiam curatam Sancti Andree de la Fatarela, diocesis Dertusensis, et quoddam simplex beneficium sine cura in Ecclesia Barchinone obtineat ac graciam Sacre Paternitatis Sanctitatis Vestre de canonicatu sub spectatione prebende ac quartorum usque ad certam sumam Ecclesie Maioricarum ${ }^{55}$.
\end{abstract}

El 18 de gener de 1395, darrera data en què hi ha notícia de mossèn Pere Pasqual a la Cancelleria Reial, el rei Joan I, volent afavorir el seu estimat capellà i domèstic, a qui, a més, li corresponia per mèrits propis, demanava al Gran Mestre de l'Hospital de Rodes la concessió del quart del delme i primícia de La Fatarella per tot el temps que mossèn Pere Pasqual fos rector de la vila "attento quod ipse Petrus pro ipso Magistro et suo ordine plurimum in hiis partibus laboravit"56.

La Capella de la Misericòrdia, que presideix la vila, ha esdevingut, com la Turris eburnea de la lletania lauretana, el millor estoig per a guardar la singular imatge gòtica de la Mare de Déu, tan rellevant per a la història de la vila i de la comarca. En aquesta imatge hi ha actualitzada la memòria històrica de mossèn Pere Pasqual i els fatarellencs i la resta de terraltins la miren com a fita singular de l'art i l'arqueologia medievals a la comarca i punt de referència de la seva història religiosa i civil, el mirall de la història i de la fe d'un poble.

${ }^{55}$ ACA, C, reg. 2012, fol. 12 r.v.

${ }^{56} \mathrm{ACA}, \mathrm{C}$, reg. 1886 , fols. 177 v. -178 r. 


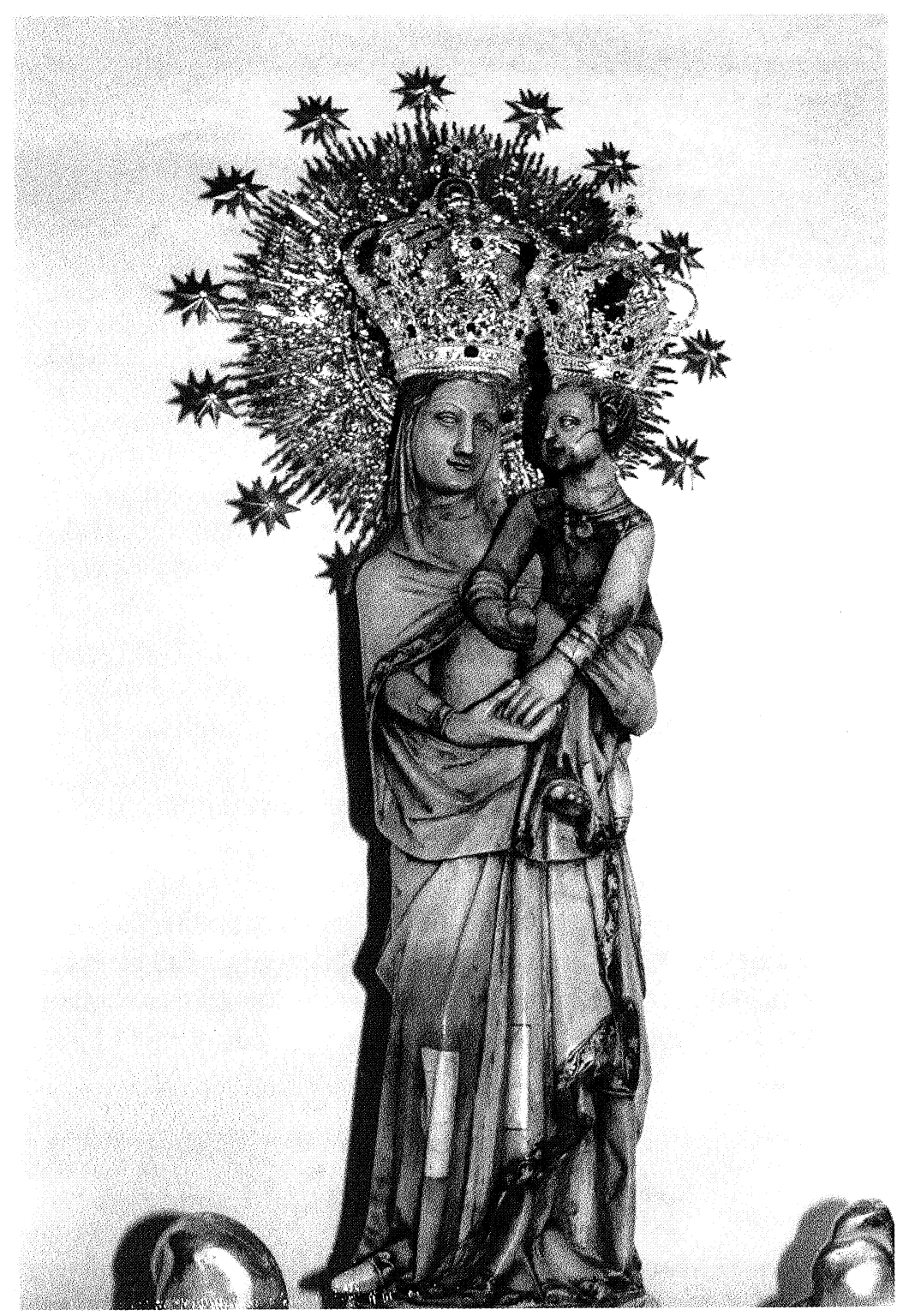

IMATGE DE LA MARE DE DÉU DE LA MISERICÒRDIA

«Anuario de Estudios Medievales», 35/2 (2005), pp. 951-970.- ISSN 0066-5061. 


\section{FONTS I BIBLIOGRAFIA}

\section{FONTS INÈDITES}

Arxiu de la Corona d'Aragó (Barcelona)

1. Cancelleria Reial

Registres de Cancelleria.

Registres 217, 381, 911, 924, 926, 931, 936, 1108, 1187, 1233, 1260, 1266, 1268, 1271, 1275, 1553, 1633, 1690, 1756, 1881, 1886, 1894, 1928, 1958, 2012, 2134, 2172, 2185, 2200, 2205, 2206, 2395, 2485.

2. Reial Patrimoni

Mestre Racional.

Registres 1773, 1824, 1884, 2406, 2407, 2591.

Arxiu Capitular de Tortosa (ACTo). Tortosa

a) Visites Pastorals.

Visita pastoral del bisbe Pedro Manrique. Any 1608.

Arxiu Històric Diocesà de Tortosa (AHDTo). Tortosa

b) Causes Beneficials

Causes Beneficials. La Fatarella. Segles XIV-XIX.

\section{FONTS PUBLICADES}

GARCIA Egea ( ${ }^{\mathrm{a}}$ Teresa), La visita pastoral a la diócesis de Tortosa del obispo Paholac. 1314, Castelló de la Plana, Diputació de Castelló, 1993.

«Anuario de Estudios Medievales», 35/2 (2005), pp. 951-970 .- ISSN 0066-5061. 


\section{BIBLIOGRAFIA}

AlANYÀ I RoIg (Josep), Els Costums d'Orta i el fur de Saragossa, dues arrels per a un conflicte, a "700 anys dels Costums d'Orta. Actes de les Jornades d'Estudi. 1996", Ajuntament d'Horta de Sant Joan, 1997.

—, El Seminari Diocesà de Tortosa, Bisbat de Tortosa, Altés, s.l., L'Hospitalet de Llobregat, 2001.

- Sermó de la Mare de Déu de la Misericòrdia en el segon centenari de la construcció de la capella (1793-1993), Barcelona, Altés, s.1., 1993.

-, Santa Maria de la Fatarella, Ajuntament de La Fatarella, Gràfiques del Matarranya, Calaceit, 2001.

-, Etnografia de la Terra Alta, Consell Comarcal de la Terra Alta, Osca, 2003.

CAMós (Narciso), Jardín de María, plantado en el Principado de Cataluña, Barcelona, 1657.

GARCIA I SANCHo (Manuel), Sacerdots diocesans fidels fins al martiri. Diòcesi de Tortosa 1936-1939, Tortosa, 1997.

José I PitARCH (Antoni) , La Mare de Déu de la Fatarella, a "La Mare de Déu de la Misericòrdia a la Fatarella”, Barcelona, Altés, s.1., 1993.

MAURI (Domingo), La Misericordia. Apunte histórico-descriptivo de su imagen y santuario de Fatarella, Reus, Tip. Rabassa y Estivill, S. en C., 1913.

-, La Misericordia. Apunte histórico-descriptivo de su imagen y santuario de Fatarella, Reus, Tip. Rabassa y Estivill, S. en C., 1913.

MiraVAll i DolÇ (Ramon), Mauri $i$ Valldeperes, Domènec, a Diccionari d'història eclesiàstica de Catalunya, vol. II, p. 597.

SERrano DAURA (Josep), Senyoriu i municipi a la Catalunya Nova (segles XII-XIX), 2 vols., Barcelona, Fundació Noguera, 2000. 